\title{
Decreased admissions and change in arrival mode in patients with cerebrovascular events during the first surge of the COVID- 19 pandemic
}

\author{
Carolin Hoyer ${ }^{*}$ (D, Lenja Weber, Vesile Sandikci, Anne Ebert, Michael Platten and Kristina Szabo
}

\begin{abstract}
Background and purpose: Investigating clinical characteristics of patients presenting with cerebrovascular events during the pandemic may provide valuable insight into further understanding the phenomenon of decreased stroke admissions during the COVID-19 pandemic.

Method: Data of patients presenting with a cerebrovascular event to the emergency department during weeks 1217/2020 were compared to data from the respective weeks in 2019.

Results: A significant reduction in the number of admissions by $35.9 \%(p=0.005)$ was observed during the COVID19 epoch. In addition, significantly more patients arrived by ambulance during the COVID-19 epoch (2019: 75.7\%, 2020: 94.2\%; $p=0.001$ ).

Conclusion: Our data may have implications as to how campaigns raising awareness for serious medical conditions in the context of the pandemic should be framed.
\end{abstract}

Keywords: COVID-19, Emergency department, Stroke

\section{To the Editor:}

Declining rates of admissions for cerebrovascular events (CVEs) and an impact on reperfusion therapy rates were observed during the first surge of the coronavirus disease 2019 (COVID-19) pandemic earlier this year. This applied regardless of the extent of COVID-19related re-allocation of resources in different countries [1-5]. Avoidance behavior caused by fear of in-hospital infection was suggested as underlying this phenomenon [6], which in the case of undiagnosed or untreated strokes may have harmful consequences. Given the current increase in the number of COVID-19 cases and an incipient second wave, it is paramount to take appropriate measures to prevent this particular aspect of

\footnotetext{
* Correspondence: carolin.hoyer@umm.de

Department of Neurology and Mannheim Center for Translationa

Neuroscience, Heidelberg University, Medical Faculty Mannheim,

Theodor-Kutzer-Ufer 1-3, 68135 Mannheim, Germany
}

recent history from repeating. Obtaining detailed demographic and clinical information of patients presenting with CVEs during the pandemic may provide valuable information to this end.

We analyzed data of patients admitted for CVEs (transient ischemic attack (TIA), ischemic stroke, intracerebral hemorrhage) to the Department of Neurology, University Medical Centre Mannheim, Germany, in weeks $1-17 / 2020$. Week $12 / 2020$, when extended measures for social distancing were implemented, was designated as the beginning of the COVID-19 epoch. Poisson regression was used to test if the rate of admissions and reperfusion therapies for ischemic stroke changed as a function of year, epoch and year-by-epoch interaction (reflecting the impact of the pandemic). We found a significant reduction of the number of admissions due to a CVE during the COVID-19 epoch by $35.9 \%$ (rate ratio $0.64,95 \%$ confidence interval (CI) $0.43-0.96, p=0.005$ );

(C) The Author(s). 2020 Open Access This article is licensed under a Creative Commons Attribution 4.0 International License, which permits use, sharing, adaptation, distribution and reproduction in any medium or format, as long as you give appropriate credit to the original author(s) and the source, provide a link to the Creative Commons licence, and indicate if changes were made. The images or other third party material in this article are included in the article's Creative Commons licence, unless indicated otherwise in a credit line to the material. If material is not included in the article's Creative Commons licence and your intended use is not permitted by statutory regulation or exceeds the permitted use, you will need to obtain permission directly from the copyright holder. To view a copy of this licence, visit http://creativecommons.org/licenses/by/4.0/. 
Fig. 1). During the observational period of 2019 and 2020, 115 and 69 CVE patients, respectively, presented. The number of reperfusion therapies decreased nonsignificantly by $27.8 \%$ (rate ratio $0.72,95 \%$ CI $0.44-1.19$, $p=0.20$ ): 23 intravenous thrombolyses (IVT) were performed in 2019, 11 in the respective period in 2020. Mechanical thrombectomy (with/without IVT), was performed in 9 and 8 patients, respectively. Group comparisons between weeks $12-17 / 2019$ vs. 2020 were performed (Table 1): No differences were found regarding age, gender and vascular risk factors, NIHSS scores, rate of minor strokes, proportion of patients with TIA and symptom-to-door times. We also identified a change in admission mode between 2019 and 2020 with significantly more admissions via ambulance in 2020 (Fig. 1, $p=0.001$ ).

Previous investigations found a decline of presentations in particular due to TIA or minor stroke during the pandemic $[1,4]$. Moreover, changes in recanalization therapy rates were attributed to underlying presentation delays [5], which may in part be caused by patients' indecisiveness as to whether they should present to a hospital. In a study of emergency department (ED) patients with neurological complaints, we previously identified a shift towards older and more severely affected patients with consecutive higher numbers of admissions to escalated care during the pandemic [7]. While we did not observe such disproportionate changes in demographics
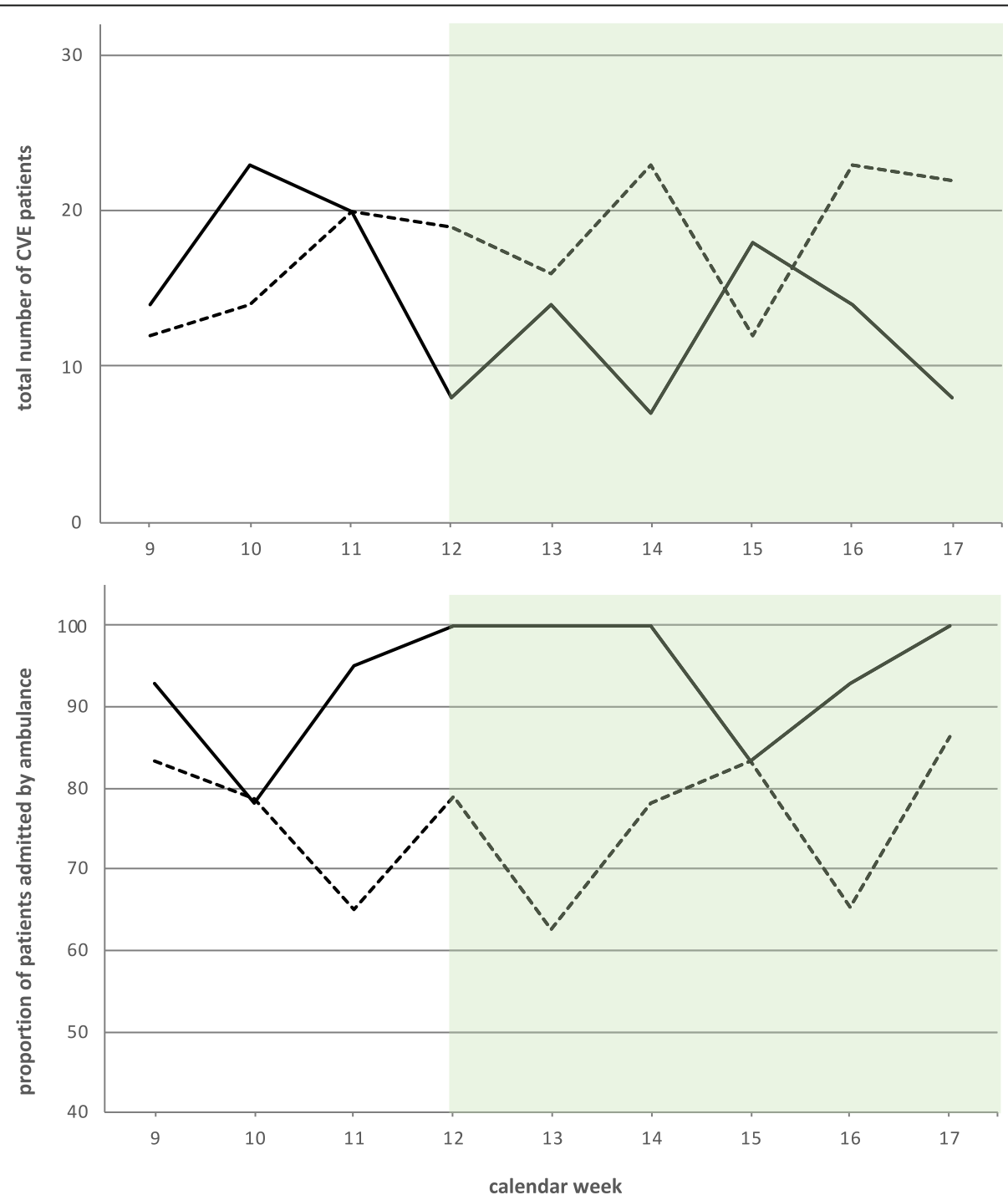

Fig. 1 Admissions due to a CVE and arrival via ambulance during weeks 9-17 in years 2019 and 2020. CVE admissions decreased by 35.9\% (upper panel) and admissions via ambulance increased by 18.5\% (lower panel) during the COVID epoch in 2020. Pale green: COVID epoch. Dotted line: year 2019, solid line: year 2020. CVE = cerebrovascular event 
Table 1 Demographics, vascular risk factors and index stroke data of patients admitted in calendar weeks $12-17$ in 2019 and 2020

\begin{tabular}{|c|c|c|c|}
\hline & $2019(n=115)$ & $2020(n=69)$ & $P$ value \\
\hline \multicolumn{4}{|l|}{ Demographics } \\
\hline Age, mean $( \pm S D)$ & $75.0(12.3)$ & $75.9(12.5)$ & 0.63 \\
\hline Gender, male, n (\%) & $51(44.3)$ & $35(50.7)$ & 0.40 \\
\hline \multicolumn{4}{|l|}{ Vascular risk factors } \\
\hline Hypertension & 85 (73.9) & $56(82.4)$ & 0.19 \\
\hline Diabetes & $34(29.6)$ & $17(25.0)$ & 0.51 \\
\hline Coronary heart disease & $19(16.5)$ & $12(17.6)$ & 0.85 \\
\hline Peripheral vascular disease & $6(5.2)$ & $1(1.5)$ & 0.26 \\
\hline Hyperlipoproteinemia & $13(11.3)$ & $6(8.8)$ & 0.60 \\
\hline Smoking & $21(18.3)$ & $10(14.7)$ & 0.54 \\
\hline \multicolumn{4}{|l|}{ Index stroke } \\
\hline Mode of admission & & & 0.001 \\
\hline Self-presenting, n (\%) & $28(24.3)$ & $4(5.8)$ & \\
\hline Admitted by ambulance, n (\%) & $87(75.7)$ & $65(94.2)$ & \\
\hline Symptom-to-door time, min ( \pm SD) & $235.7(364.8)$ & $244.9(215.6)$ & 0.88 \\
\hline \multicolumn{4}{|l|}{ Type of stroke } \\
\hline Ischemic stroke, n (\%) & $112(97.4)$ & $67(97.1)$ & 1.00 \\
\hline TIA & $31(27.0)$ & $12(17.4)$ & 0.14 \\
\hline Minor ischemic stroke $e^{a, b}$ & $32(28.3)$ & $23(34.3)$ & 0.40 \\
\hline Intracerebral hemorrhage, n (\%) & $3(2.6)$ & $2(2.9)$ & 1.00 \\
\hline NIHSS score, mean ( \pm SD) & $6.2(7.8)$ & $4.7(5.6)$ & 0.92 \\
\hline Reperfusion therapy, n (\%) & $32(27.8)$ & $19(27.5)$ & 0.97 \\
\hline IVT only & $23(20.0)$ & $11(15.9)$ & 0.49 \\
\hline IVT door-to-needle time, $\min ( \pm \mathrm{SD})$ & $30.4(13.5)$ & $28.4(6.4)$ & 0.56 \\
\hline Mechanical thrombectomy (with or without IVT) & $9(7.8)$ & $8(11.6)$ & 0.93 \\
\hline
\end{tabular}

${ }^{a}$ minor stroke defined as NIHSS score between 1 and 3

${ }^{b}$ NIHSS score data available of 113 patients from 2019 and of 67 patients from 2020, percentages adapted accordingly

NIHSS National Institute of Health Scale, IVT Intravenous thrombolysis, SD Standard deviation, TIA Transient ischemic attack

or stroke characteristics, we found a significant difference in admission modes: while overall fewer patients presented to the hospital during the COVID epoch in 2020, the vast majority of those who did arrived by ambulance. A UK investigation reported no significant reduction in ambulance call-outs for stroke during the lockdown, the authors concluded that patients do not hesitate to call an ambulance when experiencing stroke symptoms [8]. However, previous studies showed that a relevant portion of stroke patients arrive via other modes of transportation such as private or public transport [9], and that these patients are usually younger and less severely affected than patients arriving by ambulance [10]. Hence it may be precisely this subgroup of selfpresenting or privately transported patients we have seen fewer of during the pandemic. We can only speculate about the reasons behind this observation but the perceived threat of contracting an infection while waiting in often crowded EDs may be a contributing factor. It bears mentioning that ours is a single-center study examining not the entire duration of the lockdown and beyond, thus limiting the generalization of our results. Longerterm analyses are needed to further elucidate on healthrelated behaviors pertaining to if, when and how emergency presentations are initiated in the context of the pandemic. In light of our findings, it appears nonetheless adequate to advise patients to call an ambulance when noticing acute-onset neurological deficits of any kind and to frame respective campaigns accordingly. Finally, it remains essential for healthcare providers to clearly communicate that stroke care remains a priority and that swift assessment in a safe environment is guaranteed regardless of mode of presentation.

\section{Abbreviations}

COVID-19: Coronavirus disease 2019; CVE: cerebrovascular event; ED: emergency department; TIA: transient ischemic attack 


\section{Acknowledgements}

Not applicable.

\section{Authors' contributions}

Carolin Hoyer Designed and conceptualized study; major role in the acquisition of data; wrote the manuscript. Lenja Weber Major role in the acquisition of data; revised the manuscript for intellectual content. Vesile Sandikci Major role in data analysis; revised the manuscript for intellectual content. Anne Ebert Major role in data analysis; revised the manuscript for intellectual content. Michael Platten Designed and conceptualized study; revised the manuscript for intellectual content. Kristina Szabo Designed and conceptualized study; major role in the acquisition of data, revised the manuscript for intellectual content. All authors have given their approval to the final draft of the manuscript.

\section{Funding}

$\mathrm{CH}$ receives funding within the Olympia Morata Program of Heidelberg University. CH and KS receive funding within the Sonderförderlinie COVID-19 Forschung of the federal state Baden-Württemberg.

\section{Availability of data and materials}

The datasets used and/or analyzed during the current study are available from the corresponding author on reasonable request.

\section{Ethics approval and consent to participate}

The study was approved by the local ethics committee, IRB number 2018502 N-MA. Written informed consent was waived due to the retrospective character of the investigation.

\section{Consent for publication}

Not applicable.

\section{Competing interests}

The authors declare that they have no competing interests.

Received: 21 October 2020 Accepted: 2 November 2020

Published online: 16 November 2020

\section{References}

1. Diegoli, H., et al. (2020). Decrease in hospital admissions for transient ischemic attack, mild, and moderate stroke during the COVID-19 era. Stroke, 51(8), 2315-2321.

2. Hoyer, C., et al. (2020). Acute stroke in times of the COVID-19 pandemic: A multicenter study. Stroke, 51(7), 2224-2227.

3. Kansagra, A. P., Goyal, M. S., Hamilton, S., \& Albers, G. W. (2020). Collateral effect of Covid-19 on stroke evaluation in the United States. The New England Journal of Medicine, 383(4), 400-401.

4. Kristoffersen, E. S., Jahr, S. H., Thommessen, B., \& Rønning, O. M. (2020). Effect of COVID-19 pandemic on stroke admission rates in a Norwegian population. Acta Neurologica Scandinavica. https://doi.org/10.1111/ane. 13307.

5. Pop, R., et al. (2020). Impact of the COVID-19 outbreak on acute stroke pathways - insights from the Alsace region in France. European Journal of Neurology. https://doi.org/10.1111/ene.14316.

6. Wong, L. E., Hawkins, J. E., Langness, S., Murrell, K. L., Iris, P., \& Samman, A. (2020). Where are all the patients? Addressing COVUD-19 fear to encourage patients to seek emergency care NEJM Catalyst, https://catalyst.nejm.org/doi/ full/10.1056/CAT.20.0193, accessed 2020/10/20

7. Hoyer, C., Grassl, N., Bail, K., Stein, P., Ebert, A., Platten, M., \& Szabo, K. (2020). Changes in demographic and diagnostic spectra of patients with neurological symptoms presenting to an emergency department during the COVID-19 pandemic: A retrospective cohort study. Neuropsychiatric Disease and Treatment, 16, 162221-162227.

8. Holmes, J. L., Brake, S., Docherty, M., Lilford, R., \& Watson, S. (2020) Emergency ambulance services for heart attack and stroke during UK's COVID-19 lockdown. Lancet, 395(10237), e93-e94.

9. Kinsella, D., Mosley, I., \& Braitberg, G. (2018). A retrospective study investigating: Factors associated with mode of arrival and emergency department management for patients with acute stroke. Australasian Emergency Care, 21, 99-104.
10. Price, C. I., et al. (2013). An observational study of patient characteristics associated with the mode of admission to acute stroke services in north east, England. PLoS One, 8(10), e76997.

\section{Publisher's Note}

Springer Nature remains neutral with regard to jurisdictional claims in published maps and institutional affiliations.
Ready to submit your research? Choose BMC and benefit from:

- fast, convenient online submission

- thorough peer review by experienced researchers in your field

- rapid publication on acceptance

- support for research data, including large and complex data types

- gold Open Access which fosters wider collaboration and increased citations

- maximum visibility for your research: over $100 \mathrm{M}$ website views per year

At $\mathrm{BMC}$, research is always in progress.

Learn more biomedcentral.com/submissions 